\title{
Expression of Metallothionein after Administration of Aspirin, Vitamin C or Zinc Supplement in the DMH Induced Colon Carcinoma in Rat
}

\author{
Pamela Christudoss $^{1 *}$, Geeta Chacko ${ }^{2}$, Ratnasamy Selvakumar ${ }^{1}$, Jude J Fleming ${ }^{1}$, \\ Srinivasan Pugazhendhi ${ }^{3}$, George Mathew ${ }^{4}$
}

\begin{abstract}
Background: Chemoprevention refers to the use of specificnatural or synthetic chemical agents to suppress the development and progression to carcinoma. The purpose of this study was to assess the effect of aspirin, vitamin $\mathrm{C}$ or zinc on the metallothionein (MT) mRNA gene expression as well as MT protein content byimmunohistochemistry andradioimmunoassay (RIA) in 1, 2-dimethyl hydrazine (DMH) induced cancerous colonic tissuein rats. Methods: Rats were randomly divided into three groups, group 1 (aspirin), group 2 (vitamin C) group 3 (zinc), each of which was further sub divided into two groups and given subcutaneous injections of DMH (30 mg/ $/ \mathrm{kg}$ body weight) twice a week for 3 months and sacrificed at either 4 months (A-precancer model) or at 6 months (B-cancer model). The control groups were administered $0.5 \mathrm{ml}$ saline subcutaneously. All the 3 groups were simultaneouslyadministered aspirin, vitamin Cor zinc supplement respectively from the beginning till the end of the study. Results: It was observed that rats co-treated with aspirin, vitamin $\mathrm{C}$ or zinc resulted in a significant increase in the colonic MT mRNA expression in the precancer and cancer model as compared to the saline only controls. MT protein expression showed a $60 \%, 64 \%$ and $78 \%$ immunopositivity in the co-treated groups respectively. The mean MT content in the precancer and the cancer model was restored to near normal levels in all the three co-treated groups. Conclusion: These results suggest that co-administration of aspirin, vitamin $\mathrm{C}$ or zinc resulted in a significant increase in MT mRNA gene expression, MT protein expression and MT protein content which could possibly be one of the reasons for a chemo protective effect against progression to colonic cancer in a chemically induced DMH model in rat.Zinc supplement had a greater effect on metallothionein expression than aspirin or vitamin $\mathrm{C}$.
\end{abstract}

Keywords: Colon Cancer- Zinc- Metallothionein- Aspirin- Vitamin C- Dimethyl Hydrazine

Asian Pac J Cancer Prev, 19 (11), 3237-3244

\section{Introduction}

Colorectal cancer (CRC) is the third most common cancer in the world and the fourth most common cause of death (Romaguera et al., 2012). Colon carcinogenesis is characterised by steps in which the transition from normal mucosa to adenoma and further progression to carcinoma are events that offer opportunities for preventive intervention. Experimental animal models of neoplastic diseases are important in understanding the etiological, pathophysiological processes and chemo preventive approaches. The carcinogen dimethyl hydrazine (1, 2- DMH) has been widely used to study chemically induced colon cancer in rats (Rosenberg et al., 2009; Taketo and Edelman,2009).

Aspirin is a member of the Nonsteroidal anti-inflammatory drug (NSAID) class of compounds, which have been shown to be effective in blocking the initiation and progression of carcinogenesis (Nishihara et al., 2013). Epidemiological studies have suggested that the regular use of NSAID such as aspirin is associated with a reduced risk of various cancers such as colorectal, breast, lung and ovarian cancers (Cuzick et al., 2009; Rothwell et al., 2012), while animal studies have also shown that NSAIDs can decrease the initiation and/or progression of several cancers (Fischer et al., 2011). NSAIDs may inhibit colon carcinogenesis by mechanisms not known and metallothionein proteins (MTs) may be involved in this process as shown with administration of nimuselide in rats. Interestingly it has been shown that NSAIDs are reported to cause a marked increase in MT expression in rats (Escalante et al., 2006).

Intracellular ascorbic acid can protect against 
oxidative DNA damage in a dose dependent manner. Hence a link between vitamin C and DNA repair has been suggested (Sram et al., 2012). Vitamin C was found to reduce the risk of certain cancers, particularly those of the gastrointestinal tract in humans (Key, 2012). In rats, vitamin $\mathrm{C}$ showed its antioxidant effect in the colon with a decrease in carcinogenesis induced by using DMH (Williams, 2013). Induction of MT expression was observed with administration of vitamin $\mathrm{C}$ to azoxymethane (AOM) induced liver and kidney toxicity in mice (Sozmen et al., 2005)

We have previously studied the beneficial effect of vitamin $\mathrm{C}$ supplementation on colonic zinc status in association with the inhibition of progression to colon carcinogenesis in DMH treated rats (Christudoss et al, 2013).

Zinc is a structural and functional component of numerous metalloenzymes and metalloproteins. It plays a major role in the physiology of the gastrointestinal tract (Osredkar and Sustar, 2011) and it can affect some aspects of cellular metabolism such as immune function, gene expression and antioxidant defence (Dhawan and Chadha, 2010). Therefore both, an adequate supply of dietary zinc and maintenance of zinc homeostasis are crucial for normal functioning of these systems (Kambe et al., 2015). MTs are low molecular weight cysteine rich zinc binding proteins involved in many physiological processes such as intracellular storage, transport and metabolism of metal ions like zinc (Krizkova et al., 2012). Cellular MT accumulation and regulation of MT gene expression is linked directly to zinc availability from intracellular pools which in turn are influenced by dietary zinc intake (Roohani et al., 2013). MT has the capacity to scavenge reactive oxygen species (ROS) particularly the hydroxyl radical, which can induce DNA damage, leading to cellular destruction, chromosomal aberrations and finally to cancer (Rutkay-Nedecky et al., 2013). Studies indicate a protective role for MT against cellular damage caused by alkylating agent cytotoxicity, as well as its role in the homeostasis of zinc, which itself is altered in tumour growth and progression. MT has been investigated as a molecular marker of various types of cancer and the induction and expression of these proteins in normal and neoplastic cells have been associated with protection against DNA damage (Gumulec et al., 2014). All vertebrates contain two or more distinct MT isoforms grouped into two major classes designated MT-1 and MT-2. Rats are thought to synthesize only two MT isoforms. These have been demonstrated in liver, kidney, intestine, etc. (Thirumoorthy et al., 2011). Despite the evidence of a relationship between zinc status and MT concentration, the knowledge about the effects of zinc sufficient status on tissue MT gene expression, distribution and concentration in carcinogenesis is lacking.

Previously we have shown the beneficial effects of aspirin, vitamin $\mathrm{C}$ or zinc on the inhibition of histological changes in the colon towards development and progression to colon carcinogenesis in association with the maintenance of colonic tissue zinc status in DMH treated rats (Christudoss et al., 2013). Since metallothioneins are antioxidants and their expression has been related to colon carcinogenesis, the present study is an extrapolation of the animal experiment as mentioned (Christudoss et al., 2013). It was designed to assess the effect of the chemo protective agents aspirin, vitamin $C$ or zinc on MT by studying the MT mRNA expression by real time polymerised chain reaction (RT-PCR), MT protein localisation by immunohistochemistry and MT content by radioimmunoassay (RIA) in the colon of DMH treated rats in a precancer and cancer model.

\section{Materials and Methods}

\section{Animals}

Six week old adult Wistar rats (100-120g) were obtained from the Institutional animal house and housed in polypropylene plastic cages in an animal holding room under controlled conditions at $25 \pm 2^{\circ} \mathrm{C}, 50 \pm 10 \%$ humidity and 12-hour light-dark cycles. The rats were allowed water and food ad libitum, observed daily and weighed weekly. This study was approved by the Institutional Animal Experimentation Ethics Committee for the 'Purpose of Control and Supervision of Experiments on Animals (CPCSEA), (IAEC No17) and the Institutional Review board of our Institution. All ethical practices were followed for animal experimentation procedures.

\section{Experimental design}

Eighty four rats were randomly assigned to 3 groups: Group 1 (Effect of aspirin), Group 2 (Effect of Vitamin C) and Group 3 (Effect of Zinc supplement). Each group was further divided into Group A (Precancer) and Group B (Cancer). All groups were fed the same diet and maintained as described. Group A was further subdivided into control group $(n=6)$ and experimental group $(n=8)$, which received a subcutaneous dose of $0.25 \mathrm{ml}$ saline or $30 \mathrm{mg} / \mathrm{kg}$ body weight DMH dissolved in $0.25 \mathrm{ml}$ saline respectively twice a week for 3 months and were killed at 4 months. Group B was further subdivided into control group $(n=6)$ and experimental group $(n=8)$, which received a subcutaneous dose of $0.25 \mathrm{ml}$ saline or $30 \mathrm{mg} / \mathrm{kg}$ body weight $\mathrm{DMH}$ dissolved in $0.25 \mathrm{ml}$ saline respectively twice a week for 4 months and were killed at 6 months.

\section{Co-treatment with aspirin, vitamin C or zinc}

Aspirin (Acetyl salicylicacid) $350 \mathrm{mg}$ in the form of commercially available dispirin (Reckitt and Colman company Ltd; India), Vitamin C (Ascorbic Acid) $500 \mathrm{mg}$ (Roche company Ltd; India), Zinc in the form of $\mathrm{ZnSO}_{4} \cdot 7 \mathrm{H}_{2} \mathrm{O}$ (BDH diagnostics Ltd; India) were used.

All the animals of Group 1 (A) and (B) received simultaneous daily doses of $0.5 \mathrm{ml}$ acetylsalicylic acid (Aspirin) $60 \mathrm{mg} / \mathrm{kg} /$ day by gavage till end of study. Group 2 (A) and (B) received simultaneous daily doses of $0.5 \mathrm{ml}$ Vitamin C $50 \mathrm{mg} / 5 \mathrm{~g}$ diet /day by gavage till end of the study. Group 3 (A) and (B) received simultaneous daily doses of $0.5 \mathrm{ml}$ zinc supplement $400 \mu \mathrm{g} /$ day by gavage till the end of the study.Aspirin, Vitamin C and zinc sulphate was weighed and dissolved in sterile water. The dose used in this study for each of these 3 supplements was the same as of our previous study (Christudoss et al., 2013). 


\section{Tissue preparation}

The colon of the rats of all the groups was harvested, slit length wise and checked for abnormalities. Any lesion detected was resected and small portions were cut out from the resected area, preweighed (approximately 10 $\mathrm{mg}$ ), frozen using liquid nitrogen and then stored at $-70{ }^{\circ} \mathrm{C}$ until analysis for estimation of metallothionein content by $\mathrm{Cd}^{109}$ assay and MT mRNA expression by RT-PCR. The immunohistochemical expression of metallothionein was analysed from formalin fixed, paraffin embedded tissues used for histopathology. The portion of tissue used for all the MT estimations were from the same resected area of the colonfor each rat.

\section{Estimation of MT content}

MT content inthe colonic tissue was determined by $\mathrm{Cadmium} /$ haemoglobin $(\mathrm{Cd} / \mathrm{Hb}) \mathrm{RIA}$ as previously described (Eaton and Toal, 1982). Protein concentration in the supernatant was determined by the method of Lowry et al., (1951). Dataobtained by this method are expressed as mean $\mathrm{nmol} \mathrm{Cd} / \mathrm{mg}$ protein.

\section{Immunohistochemical localization of MT}

MT localization in large intestine was determined using standard procedures for immunohistochemistry staining (Szczurek et al., 2001). Briefly, immunohistochemistry was performed on 5 micron sections of formalin-fixed paraffin-embedded tissue using a mouse monoclonal antibody E9 (Dako Ltd; DSS Image Tech- India, diluted 1:50 in phosphate buffered saline) which reacts with MT-1 and MT- 2.Dako Envision system (system labelled polymer-HRP, antimouse, Dako, DSS Image Tech- India) was used for detection and the reaction product was visualized with the chromogen DAB (3- 3' -diaminobenzidine, Dako). Tissues were counterstained with Harris Haematoxylin. Normal rat colon served as the positive control.

\section{Immunohistochemical evaluation}

The extent and localisation of MT immunostaining in the crypts was estimated and expressed as a percentage of the total number of crypts. Immunostaining (nuclear, cytoplasmic or membrane cytoplasmic) was calculated as the percentage of positive staining in cells in relation to the total cell number in representative fields. A cell was considered immunopositive if either the nucleus or the cytoplasm or both showed positive staining irrespective of intensity. However, it was our experience that immunopositivity was uniformly strong in all cases and equivocal immunostaining was rarely observed.

\section{RNA isolation, Reverse Transcription Polymerase chain reaction}

Total RNA (200 ng) was converted into cDNA using Euroscript reverse transcriptase core kit (RT-RTCK-03, Eurogentec, Genex- India). Briefly, the conversion mixture contained final concentration of $1 \mathrm{x}$ buffer, $5 \mathrm{mM}$ magnesium chloride $\left(\mathrm{MgCl}_{2}\right), 500 \mu \mathrm{M}$ of each dNTPs, $2.5 \mu \mathrm{M}$ random nonamer, $0.4 \mathrm{u} / \mu \mathrm{l}$ of RNAse inhibitor, $1.25 \mathrm{u} / \mu \mathrm{l}$ of Eurotranscript. The cDNA conversion was carried out in PTC-150 Minicycler (Bio-Rad, USA) with an initial activation step for $10 \mathrm{~min}$ at $25^{\circ} \mathrm{C}$ followed by a reverse transcription step for $30 \mathrm{~min}$ at $48^{\circ} \mathrm{C}$, and a final inactivation step for $5 \mathrm{~min}$ at $95^{\circ} \mathrm{C}$. Metallothionein expression in cDNA samples was measured by real time quantitative PCR using Hot gold star DNA polymerase kit (Eurogentec, Belgium) in Chromo- 4 real time PCR machine (Bio-Rad, USA). GAPDH gene is a well-known housekeeping gene used for normalization of expression and the primers from previously described studies (Liu et al., 2003) were used for the quantitation. The primer sequences used for metallothionein (MT-1) were as given in our previous study (Christudoss et al., 2016). The primers were verified with the NCBI BLAST search engine. PCR conditions were optimized by gradient PCR and the specificity of amplicons was confirmed by electrophoresing on $2 \%$ agarose gel. The threshold cycle $(\mathrm{Ct})$ values for all the samples were measured in replicates and the expression was quantitated using the following

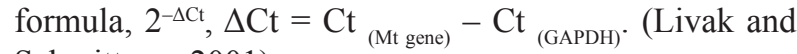
Schmittgen, 2001).

\section{Statistical Analysis}

Data are expressed as Mean \pm SD. Differences between groups were analysed using Non -Parametric test- Mann Whitney U test and ANOVA. A difference was considered statistically significant when the probability associated with it was less than 0.05 ( $p$ value $<0.05$ ).

\section{Results}

The results of MT mRNA expression, protein

Table 1. Test of Significance (P - VALUE) (\% Increase in MT m RNA, MT-IH, MT Content of Respective Co - treated Groups Compared with theDMH -test Group)

\begin{tabular}{|c|c|c|c|c|c|c|}
\hline \multirow[b]{2}{*}{ GROUP } & \multicolumn{2}{|c|}{ MT mRNA } & \multicolumn{2}{|c|}{ MT -IH* } & \multicolumn{2}{|c|}{ MT -content } \\
\hline & Precancer $(\% \uparrow)$ & Cancer $(\% \uparrow)$ & Precancer $(\% \uparrow)$ & Cancer $(\% \uparrow)$ & Precancer $(\% \uparrow)$ & Cancer $(\% \uparrow)$ \\
\hline $\begin{array}{l}\text { (Aspirin + DMH) } \\
\text { Vs DMH -test }\end{array}$ & $\begin{array}{c}2.6 \text { fold } \uparrow \\
170 \% \\
(\mathrm{P}<0.001)\end{array}$ & $\begin{array}{c}24.6 \text { fold } \uparrow \\
>2000 \% \\
(\mathrm{P}<0.0001)\end{array}$ & $\begin{array}{c}53 \% \\
(\mathrm{P}<0.05)\end{array}$ & $\begin{array}{c}200 \% \\
(\mathrm{P}<0.005)\end{array}$ & $\begin{array}{c}36 \% \\
(\mathrm{P}<0.05)\end{array}$ & $\begin{array}{c}109 \% \\
(\mathrm{P}<0.005)\end{array}$ \\
\hline $\begin{array}{l}(\text { Vit C + DMH }) \\
\text { Vs DMH -test }\end{array}$ & $\begin{array}{c}2.33 \text { fold } \uparrow \\
140 \% \\
(\mathrm{P}<0.001)\end{array}$ & $\begin{array}{c}25 \text { fold } \uparrow \\
>2000 \% \\
(\mathrm{P}<0.0001)\end{array}$ & $\begin{array}{c}55 \% \\
(\mathrm{P}<0.05)\end{array}$ & $\begin{array}{c}220 \% \\
(\mathrm{P}<0.005)\end{array}$ & $\begin{array}{c}39 \% \\
(\mathrm{P}<0.05)\end{array}$ & $\begin{array}{c}116 \% \\
(\mathrm{P}<0.005)\end{array}$ \\
\hline $\begin{array}{l}(\text { Zinc }+ \text { DMH }) \\
\text { Vs DMH -test }\end{array}$ & $\begin{array}{c}3.6 \text { fold } \uparrow \\
276 \% \\
(\mathrm{P}<0.001)\end{array}$ & $\begin{array}{c}33 \text { fold } \uparrow \\
>3000 \% \\
(\mathrm{P}<0.0001)\end{array}$ & $\begin{array}{c}77 \% \\
(\mathrm{P}<0.05)\end{array}$ & $\begin{array}{c}290 \% \\
(\mathrm{P}<0.005)\end{array}$ & $\begin{array}{c}44 \% \\
(\mathrm{P}<0.05)\end{array}$ & $\begin{array}{c}143 \% \\
(\mathrm{P}<0.005)\end{array}$ \\
\hline
\end{tabular}

*MT-IH metallothionein immunohistochemistry 
a- Precancerous

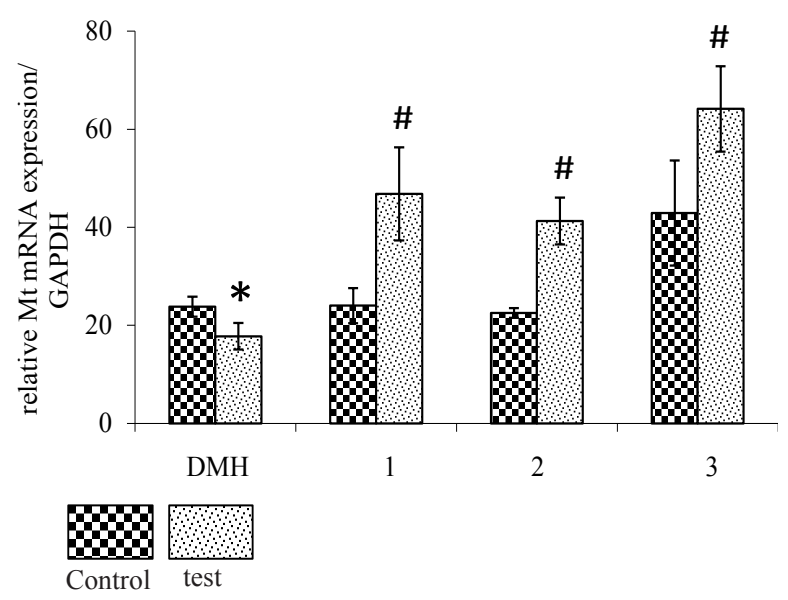

b-Cancerous

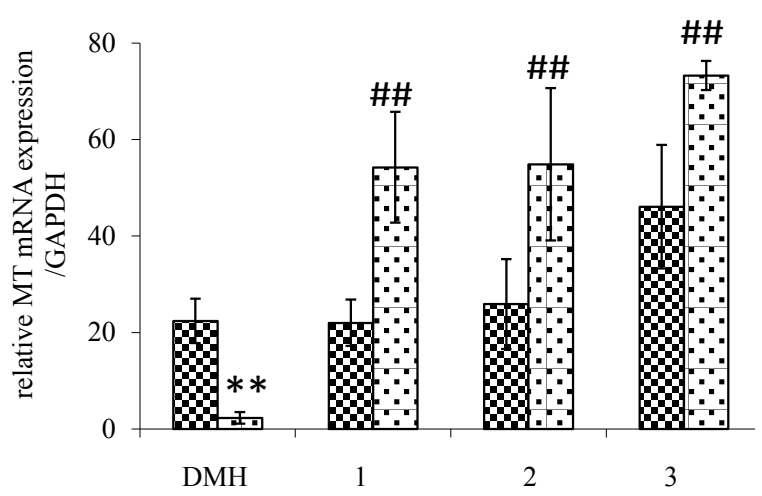

Figure 1. Metallothionein mRNA Expression in Large Intestineof DMH co- treated Rats Measured by RT-PCR in (a) Precancerous (4 months) and (b) Cancerous (6 months). Values are represented as mean $\pm \mathrm{SD}$; ${ }^{*}<0.01$; $* * \mathrm{p}<0.001$ (DMH vs. saline control); \# $\mathrm{p}<0.001$; \# \# $\mathrm{p}<0.0001$. (Co-treated group vs. DMH-Test group.) Control n, 6; test, 8; @ DMH, Control, saline Test, DMH; 1, Control, saline + aspirin Test, DMH + aspirin; 2, Control, saline + vit. CTest, DMH + vit. C; 3, Control, saline + zinc Test, DMH + zinc; @ \{reproduced with permission from reference (DOI, 10.4103/0973-1482.179107. Christudoss P, Chacko G, Selvakumar R, et al (2016) Metallothionein in dimethylhydrazine-induced colonic precancerous and cancerous model in rat. Journal of cancer research and therapeutics, 12 (4), 1307-12\}.

localisation and content observed in the present study in DMH treated rats supplemented with aspirin, vitamin C or zinc are compared with the results observed in our previous study in which rats were given the same DMH doses but without any supplement (Christudoss et al., 2016). These data (DMH only and saline only groups) are shown to facilitate comparison. The results of all the 3 co-treated test groups are compared with the saline only control group which is similar to the co-treated control groups as in aspirin and vitamin C. Only zinc + saline control group showed a significant increase in MT mRNA expression.

DMH and co- treatment with aspirin/vitamin C/zinc in the precancerous group

As shown in Figure 1a, in the precancer model, the $\mathrm{DMH}$ treated rats given aspirin, resulted in a significant increase in the mean colonic MT mRNA expression ( $94 \%, 46 \pm 9.5$ vs $24 \pm 2.03, \mathrm{p}<0.005)$, with vitamin $\mathrm{C}(74 \%, 41.3 \pm 8$ vs $24 \pm 2.03, \mathrm{p}<0.005)$, and with zinc $(170 \%, 64.2 \pm 8.7 \mathrm{vs}, 24 \pm 2.03, \mathrm{p}<0.001)$ as compared with saline only controls.

The immunohistochemical localisation of colonic MT in the cotreated groups of the precancerous model showed mean immunopositive staining 69\%, 70\%, and $80 \%$ respectively which was near to the $95 \%$ immunopositive staining in saline controls (Figure $2 \mathrm{a}$ ). The mean colonic MT content in the precancer model showed no significant difference in all the 3 co treated groups: aspirin $(0.122 \pm 0.01$ vs. $0.137 \pm 0.01)$ with vitamin $\mathrm{C}(0.125 \pm 0.018$ vs $0.139 \pm 0.043)$ and zinc $(0.130 \pm$ 0.013 vs $0.159 \pm 0.058)$ as compared with saline controls (Figure 3a).

Whereas when each of the co-treated test groups were compared with the DMH only test group, a greater
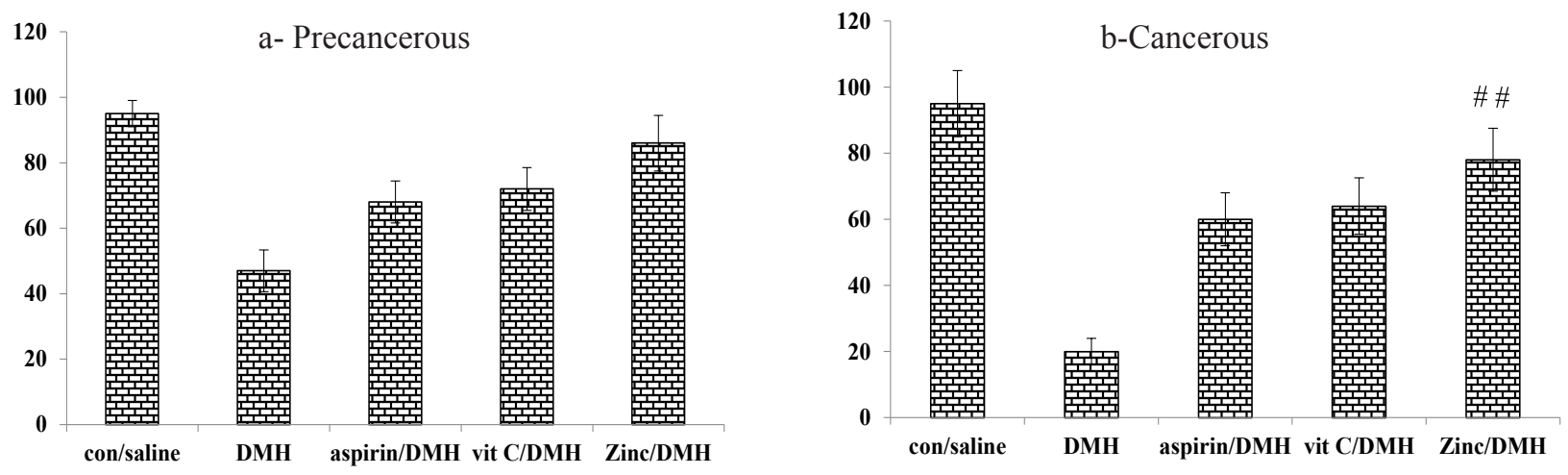

Figure 2. Percentage of Metallothionein Positive Staining in Largeintestine of DMH Treated Rats and Rats Co treated with Aspirin, Vitamin $\mathrm{C}$ or Zinc. Values are represented as mean $\pm \mathrm{SD}$. ${ }^{*} \mathrm{P}<0.01,{ }^{*} * \mathrm{p}<0.001$ (DMHvs. saline control); \# $\mathrm{P}<0.05$, \#\# $\mathrm{p}<0.005$ (co-treated group vs. DMH -Test group.) Control n, 6, test, 8; @ C/ saline, - animals treated with saline; @ DMH, -- animals treated with DMH; Aspirin/DMH, - animals treated with DMH + aspirin; Vit C/ DMH, - animals treated with DMH + vit. C; Zinc /DMH, - animals treated with DMH + zinc; @ \{reproduced with permission from reference (DOI, 10.4103/0973-1482.179107\}. 

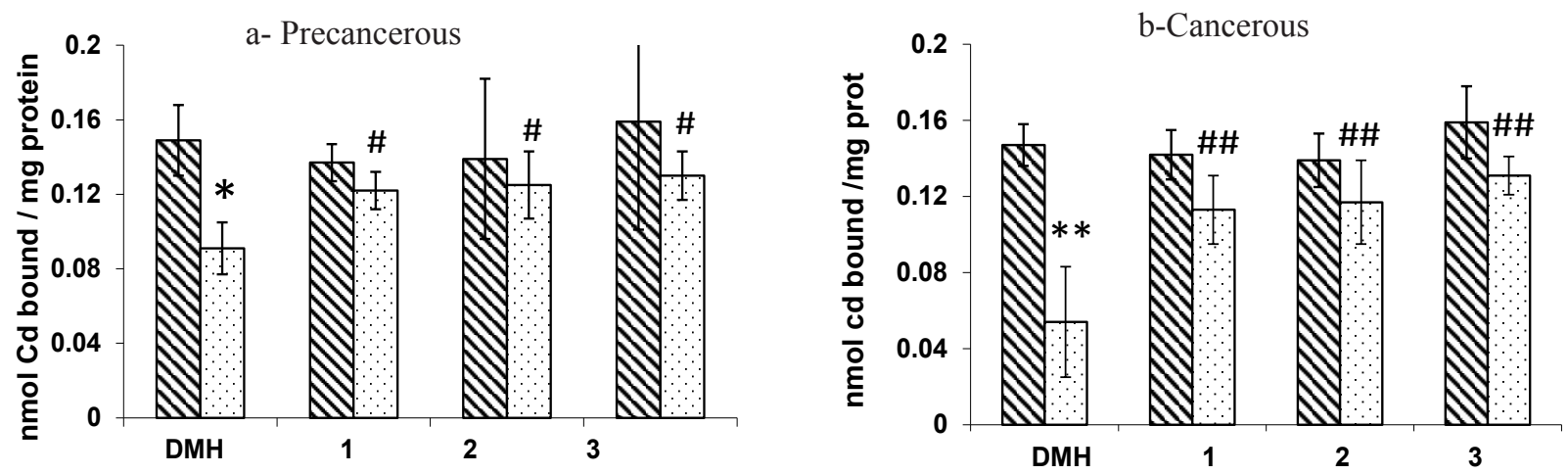

Figure 3. Metallothionein Content in Large Intestine in Rats Measured by Cd ${ }^{109}$ Affinity Binding Assay in DMH Cotreated Groups (A) Precancerous (4 months) and (B) Cancerous (6 months). Values are represented as mean $\pm \mathrm{SD}$. * $\mathrm{p}<0.01, * * \mathrm{p}<0.001$ (DMH vs saline control), \# $\mathrm{P}<0.05$, \#\# $\mathrm{p}<0.005$ (co-treated group vs. DMH -Test group.) Control n, 6; test, 8;@DMH, Control, saline; Test, DMH; 1, Control, saline + aspirin; Test, DMH + aspirin; 2, Control, saline + vit C; Test, DMH + vit. C; 3, Control, saline + zinc; Test, DMH + zinc; @ \{reproduced with permission from reference DOI, 10.4103/0973-1482.179107\}

statistical significant increase was demonstrated in MT mRNA expression $(\mathrm{p}<0.001)$, in MT protein immunostaining $(\mathrm{p}<0.05)$ and in MT content $(\mathrm{p}<0.05)$. (Statistical significance shown in Table 1).

A

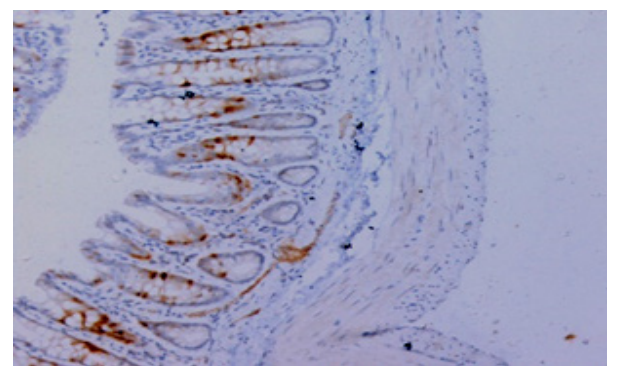

B

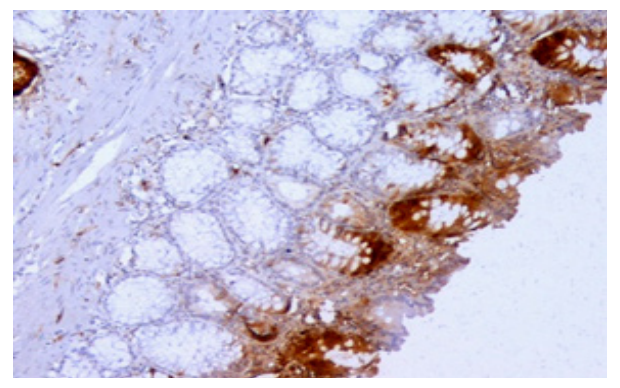

C

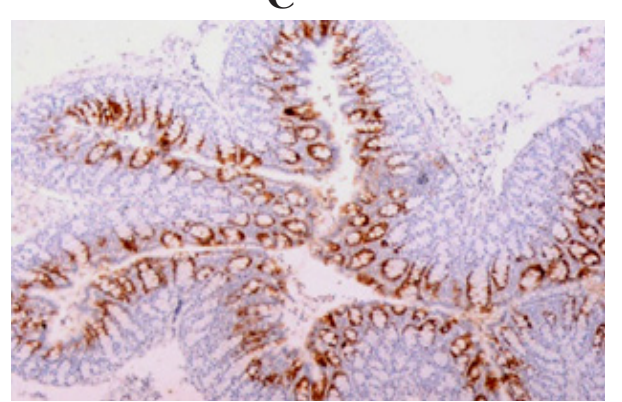

Figure 4. Immunohistochemical Localisation of Metallothionein (MT) in the Cancerous Cotreated Groups (a) $\mathrm{DMH}+$ Aspirin- showing 60\% MT Expression (b) $\mathrm{DMH}+$ Vitamin C Showing 64\% MT Expression (e) $\mathrm{DMH}+$ Zinc Showing 78\% MT Expression (Magnification $40 \mathrm{x}$ )
DMH and co- treatment with aspirin/vitamin C/zinc in the cancerous group

As shown in Figure 1b, in the cancer model, the DMH treated rats given aspirin resulted in a significant increase in mean colonic MT mRNA expression $(142 \%, 54.2 \pm 11.5$ vs. $22.4 \pm 4.6$, p $<0.005)$, with vitamin $\mathrm{C}(145 \%, 55 \pm 15.8$ vs. $22.4 \pm 4.6, \mathrm{p}<0.005)$ and zinc (mean $226 \%, 73 \pm 3.0$ vs. $22.4 \pm 4.6, \mathrm{p}<0.001$ ) as compared with saline only controls.

Immunohistochemical analysis of colonic MT in the cancer group in the rats co-treated with aspirin, vitamin $\mathrm{C}$ or zinc resulted in a mean MT immunopositive staining of $60 \%, 64 \%$, and $78 \%$ respectively (Figure $2 \mathrm{~b}$ and Figure 4 ), as compared with $95 \%$ immunopositive staining in saline controls. The mean colonic MT content in the cancer group showed no significant decrease difference in rats co treated with aspirin $(0.115 \pm 0.018$ vs. $0.140 \pm 0.013)$, with vitamin $C(0.117 \pm 0.022$ vs. $0.139 \pm 0.014)$ and zinc $(0.131 \pm 0.01 \mathrm{vs} 0.159 \pm 0.019)$ as compared with saline only controls (Figure 3b).

Whereas when each of the co- treated test groups were compared with the DMH only test group, a greater statistical significant increase in MT mRNA expression $(p<0.0001)$, MT immunohistochemical staining $(p<0.005)$ and in MT content $(\mathrm{p}<0.005)$ were observed. (Statistical significance shown in Table 1). The zinc cotreated group showed a greater increase in MT mRNA expression, MT immunopositive staining and MT content.

\section{Discussion}

Chemoprevention i.e.suppression of the carcinogenic process in the colon with non-pharmacologic or pharmacologic agents is an area of considerable research interest and activity. The involvement of MT is seen in many pathophysiological processes such as detoxification, cell proliferation, apoptosis and protection against oxidative damage. Since MT is a zinc protein, this present study has evaluated the expression of MT at all three levels in the colon of DMH treated rats supplemented with aspirin, vitamin $\mathrm{C}$ or zinc. It was observed that these results correlate with the increase and maintenance in 
colonic tissue zinc status observed in the same rats that were used in our previous study (Christudoss et al., 2013).

Studies have shown that down regulation of MT expression is associated with worse prognosis in colon cancer and in other cancers in humans and that there is a possibility that MT reinduction using demethylating or other agents could be used for colorectal cancer therapy. (Schmitz et al., 2009; Arriaga et al., 2012). Although MT expression in colorectal cancer has been studied the effect of supplements such as zinc, vitamin $\mathrm{C}$ or Aspirin on the MT expression has not been dealt with extensively. However there is abundance of evidence in the literature on the role of nutrition on colorectal and other cancers. Evidence from clinical trial populations suggest that low dose aspirin reduces the risk of colorectal cancer (Algra and Rothwell, 2012; Rothwell et al., 2012; Cook et al., 2013). A few other studies have shown the protective effect of the NSAID aspirin on DMH induced colon carcinogenesis (Liao et al., 2012; Gray et al., 2017). In this present study, it was demonstrated that co-treatment with aspirin administered at the initiation stage was able to increase the colonic MT mRNA expression, MT protein expression and MT content in both precancerous and cancerous groups. In the cancerous group there was a 24.6 fold increase in MT mRNA expression which was reflected in an increase in the MT immunohistochemical expression $(200 \%)$ along with a concomitant increase in MT protein content (109\%) as compared with the DMH only treatment group. Our study is in agreement with a study reported by Escalante et al., (2006), that ingestion of the NSAID -Nimesulide along with administration of DMH was associated with an increase in the number of MT-over expressing colonic epithelial cells, as measured by Immunohistochemistry, when compared to the DMH only treated rats. Comparison of the MT mRNA expression, protein expression and MT content in the large intestine in DMH treated rats without aspirin as shown in our previous study (Christudoss et al., 2016) and with aspirin therapy as observed in the present study demonstrates significant improvement in the metallothionein parameters in the aspirin co-treated group.

Vitamin $\mathrm{C}$ has been used to complement the treatment of cancer, aiding in patient survival and quality of life. Various studies have shown the therapeutic use of vitamin $\mathrm{C}$ in Phase $1 / 2$ Clinical trial for colon cancer and cancer cell lines and such therapy can benefit patients by improving their prognosis and therapeutic efficacy.(Mikirova et al., 2012; Stephenson et al., 2013; Pires et al., 2016). Studies have shown that vitamin C could have a possible role against cancer (Key, 2011). In this present study, we observed that co treatment with ascorbic acid (vitamin C) administered from the initiation stage, mediated up-regulation of colonic MT mRNA gene expression, protein expression and MT content both in precancerous and cancerous groups. When compared with the DMH only test group, the increase in MT mRNA expression was 25 fold with a concomitant raise in protein expression (220\%) and MT content (116\%). This study for the first time shows a significant improvement in metallothionein expression in vitamin $\mathrm{C}$ cotreated rats. These observations correlate with our previous studies on protective effect of vitamin $\mathrm{C}$ in $\mathrm{DMH}$ induced colon carcinoma and hence it could be suggested that vitamin $\mathrm{C}$ mayexert its protective role through induction of MT gene expression.

Many studies have shown the beneficial effect of zinc supplement in anticancer therapeutics in humans and colon cancer cells and is associated with a decreased risk of both proximal and distal colon cancers (Puca et al., 2011; Zhang et al., 2011; Pericelous et al., 2013). The availability of zinc derived from dietary zinc supply is required for both MT gene expression and protein degradation which in turn is necessary for cellular accumulation of metallothionein (Roohani et al., 2013). In the present study, it was observed that DMH treated rats supplemented with zinc from the initiation stage resulted in a significant increase in colonic MT mRNA in both precancerous and cancerous groups (3.6 fold and 33 fold respectively), which was reflected in the simultaneous increase in the immunohistochemical localisation of the MT protein (290\%, cancer group) along with a concomitant raise in MT protein content $(143 \%$, cancer group) as compared with the DMH test group. Our results are in agreement with other studies that zinc supplementation has an effect on MT concentration and its mRNA synthesis in various tissues of growing rats, including esophagus and intestine (Liu et al., 2005) and in human Leukocytes (Hennigar, et al., 2016). These studies demonstrate the responsiveness of MT expression to zinc consumption in humans and rats and are enhanced by observations that zinc increases the susceptibility of cells to apoptosis (Kocdor et al., 2015). As observed in Human studies and in cell lines, reinduction of MT's with zinc administration may have therapeutic value by diminishing the aggressiveness of the CRC tumours and thus sensitize these tumours to chemotherapeutic agents (Arriaga et al., 2014; Arriaga et al., 2017). In normal humans, it was observed that zinc supplement upregulates MT gene expression (Chu et al., 2015; Sharif et al., 2015). A striking observation in our study was that the metallothionein mRNA expression in the zinc + saline control group, itself showed approximately a100\% increase when compared to the saline only controls demonstrating that zinc supplementation increases MT expression. In our present study the presence of strong MT staining after zinc supplementation against the absence of MT staining in surface epithelial cells in response to DMH only as demonstrated in our previous study (Christudoss et al., 2016) could probably indicate adequacy of oral zinc treatment.This observation is in agreement with a study carried out where there was no MT staining in zinc deficient rat intestinal cells, but after zinc repletion strong MT staining was seen in the cells (AL-Gindan et al., 2009).

At present information on the role of MT in colon cancer is limited. The current results complement our earlier studies on DMH induced colon carcinogenesis which demonstrated a substantial reduction in colonic tissue Zn and MT expression (Christudoss et al., 2012; Christudoss et al., 2016). Besides, in another study of ours, cotreatment with either aspirin, vitamin $\mathrm{C}$ or zinc at the initiation stage showed a protective effect in $\mathrm{DMH}$ induced colon cancer in rat probably by inhibiting the formation of colonic preneoplastic and neoplastic lesions which was 
associated with an increase in colonic tissue zinc levels and maintenance of zinc containing enzymes (Christudoss et al., 2013). In addition to the above findings in our rat model, this present study further demonstrates that cotreatment with any of the 3 supplements administered at the initiation stage, showed an associated increase in metallothionein at all three levels as in mRNA gene expression, MT protein localisation and MT content in the colon of DMH treated rats. Overall, these observations could indicate that administration of supplements such as aspirin, vitamin $\mathrm{C}$ or zinc in a $\mathrm{DMH}$ colon carcinoma model might restore zinc status which could probably be a potent inducer of MT expression (Arriaga et al., 2014). Moreover from our studies, it has been demonstrated that co treatment with zinc resulted in a greater increase in zinc status and MT parameters.

Since MT's are progressively silenced during colon cancer the possibility of reinducing their expression might thus represent a novel strategy to improve responses to therapeutic agents. The results suggest the potential of MT expression as a candidate biomarker in colon cancer and the utilization of supplements zinc, aspirin or vitamin $\mathrm{C}$ in colon cancer prevention and treatment which could be beneficial to patients .Further studies are warranted to define the mechanisms of the increase in metallothionein and its role in colonic carcinogenesis in rats. More broadly the data provide the beginnings of a molecular understanding of how these supplements help in restoring metallothionein expression in animal model.

\section{Acknowledgements}

I would like to thank theInstitutional Research Grant, Christian Medical College and Hospital, Vellore, India -for their financial support towards this work.

I would also like to thank Dr.B.S. Ramakrishna, Professor, Department of G.I. Sciences, Christian Medical College and Hospital, Vellore for granting me the permission to carry out molecular techniques in his department.

\section{References}

Al-Gindan Y, Shawarby M, Noto A, Taylor CG (2009). Intestinal inflammation in rats Induces metallothionein in colonic submucosa. J Clin Biochem Nutr, 44, 131-41.

Algra AM, Rothwell PM (2012). Effects of regular aspirin on long-term cancer incidence and metastasis: a systematic comparison of evidence from observational studies versus randomised trials. Lancet Oncol, 13, 518-27.

Arriaga JM, Levy EM, Bravo AI, et al (2012). Metallothionein expression in colorectal cancer: relevance of different isoforms for tumor progression and patient survival. Hum Pathol, 43, 197-208.

Arriaga JM, Greco A, Mordoh J, Bianchini M (2014). Metallothionein $1 \mathrm{G}$ and zinc Sensitize human colorectal cancer cells to chemotherapy. Mol Cancer Ther, 13, 1369-81.

Arriaga JM, Bravo AI, Mordoh J, Bianchini M (2017). Metallothionein $1 \mathrm{G}$ promotes the differentiation of HT-29 human colorectal cancer cells. Oncol Rep, 37, 2633-51.

Christudoss P, Selvakumar R, Pulimood AB, Fleming JJ, Mathew $\mathrm{G}$ (2012). Zinc and zinc Related enzymes in precancerous
Metallothionein in Colonic Cancer after Supplements

and cancerous tissue in the colon of dimethyl Hydrazine treated rats. Asian Pac J Cancer Prev, 13, 487-92.

Christudoss P, Selvakumar R, Pulimood AB, Fleming JJ, Mathew $\mathrm{G}$ (2013). Protective role of aspirin, vitamin $\mathrm{C}$ and zinc and their effects on zinc status in the DMH-induced colon carcinoma model. Asian Pac J Cancer Prev, 14, 4627-34.

Christudoss P, Chacko G, Selvakumar R, et al (2016). Expression of metallothionein in Dimethyl hydrazine-induced colonic precancerous and cancerous model in rat. J Can Res Ther, 12, 1307-12.

Chu A, Foster M, Ward S, et al (2015). Zinc-induced upregulation of metallothionein (MT)- 2A is predicted by gene expression of zinc transporters in healthy adults. Genes Nutr, 10, 44.

Cook NR, Lee IM, Zhang SM, Moorthy MV, Buring JE (2013). Alternate-day, low-dose aspirin and cancer risk: long-term observational follow-up of a randomized trial. Ann Intern Med, 159, 77-85.

Cuzick J, Otto F, Baron JA, et al (2009). Aspirin and non-steroidal anti-inflammatory drugs for cancer prevention: an international consensus statement. Lancet Oncol, 10, $501-7$.

Dhawan DK, Chadha VD (2010). Zinc: A promising agent in dietary chemoprevention of cancer. Indian J Med Res, 132, 676-82.

Eaton DL, Toal BF (1982). Evaluation of the Cd/hemoglobin affinity assay for the rapid determination of metallothionein in biological tissues. Toxicol Appl Pharmacol, 66, 134-42.

Escalante RD, Oliveria EC, CunhaFQ, Vespucio MV, Riberio A (2006). Trypanosoma cruzi infection and/or administration of the nonsteroidal anti-inflammatory nimesulide increase the number of colonic crypts overexpressing metallothioneins in rat colon carcinogenesis. Braz J Med Biol Res, 39, 895 -9.

Fischer SM, Hawk E, Lubet RA (2011). Non-steroidal anti-inflammatory drugs and coxibsin chemoprevention: A commentary based primarily on animal studies. Cancer Prev Res (Phila), 4, 1728-35.

Gray RT, Cantwell MM, Coleman HG, et al (2017). Evaluation of PTGS2 Expression, PIK3CA mutation, Aspirin use and colon cancer survival in a population-based cohort study. Clin Transl Gastroenterol, 8, e91.

Gumulec J, Raudenska M, Adam V, Kizek R, Masarik M (2014). Metallothionein - immunohistochemical cancer biomarker: A meta-analysis. PLoS One, 9, e85346.

Hennigar SR, KelleyAM, McClung JP (2016).Metallothionein and Zinc transporter expression in circulating human blood cells as biomarkers of Zinc status: a systematic review. $A d v$ Nutr, 7, 735-46.

Kambe T, Tsuji T, Hashimoto A, Itsumura N (2015). The physiological, biochemical, and Molecular roles of zinc transporters in Zinc Homeostasis and Metabolism. Physiol Rev, 95, 749-84.

Key TJ (2011). Fruit and vegetables and cancer risk. Br J Cancer, 104, 6-11

Kocdor H, Ates H, Aydin S, et al (2015). Zinc supplementation induces apoptosis and enhances antitumor efficacy of docetaxel in non-small-cell lung cancer. Drug Des Devel Ther, 9, 3899-909.

Krizkova S, Ryvolova M, Hrabeta J, et al (2012) Metallothioneins and zinc in cancer diagnosis and therapy. Drug Metab Rev, 44, 287-301.

Liao LM, Vaughan TL, Corley DA, et al (2012).Nonsteroidal anti-inflammatory drug use reduces risk of adenocarcinomas of the esophagus and esophago gastric junction in a pooled analysis. Gastroenterology, 142, 442-52.

Liu CG, Zhang L, Jiang Y, et al (2005). Modulation of gene expression in precancerous rat esophagus by dietary zinc deficit and replenishment. Cancer Res, 65, 7790-9.

Asian Pacific Journal of Cancer Prevention, Vol $19 \mathbf{3 2 4 3}$ 
Liu J, Lei D, Waalkes MP, Beliles RP, Morgan DL (2003). Genomic analysis of the rat lung following elemental mercury vapour exposure. Toxicol Sci, 74, 174-81.

Livak KJ, Schmittgen TD (2001). Analysis of relative gene expression data using real-time quantitative PCR and the 2(- Delta Delta C (T)) Method. Methods, 25, 402-8.

Lowry OH, Rosebrough NJ, Farr AL, Randall RJ (1951). Protein measurement with the Folin phenol reagent. J Biol Chem, 193, 265-75.

Mikirova N, Casciari J, Rogers A, Taylor P (2012). Effect of high-dose intravenous vitamin $\mathrm{C}$ on inflammation in cancer patients. J Transl Med, 10, 189.

Nishihara R, Lochhead P, Kuchiba A, et al (2013). Aspirin use and risk of colorectal cancer according to BRAF Mutation Status. JAMA, 309, 2563-71.

Osredkar J, Sustar N (2011). Copper and Zinc, biological role and significance of Copper/Zinc imbalance. J Clinic Toxicol, s3-001.

Pericleous M, Mandair D, Caplin ME (2013). Diet and supplements and their impact on colorectal cancer. $J$ Gastointest Oncol, 4, 409-23

Pires AS, Marques CR, Encarnacao JC, et al (2016). Ascorbic acid and colon cancer: an oxidative stimulus to cell death depending on cell profile. Eur J Cell Biol, 95, 208- 18.

Puca R, Nardinocchi L, Porru M, et al (2011). Restoring p53 active conformation by zinc increases the response of mutant p53 tumor cells to anticancer drugs. Cell Cycle, 10, 1679-89.

Romaguera D, Vergnaud AC, Peeters PH, et al (2012). Is concordance with World Cancer Research Fund/American Institute for Cancer Research guidelines for cancer prevention related to subsequent risk of cancer? Results from the EPIC study. Am J Clin Nutr, 96, 150-63.

Roohani N, Hurrell R, Kelishadi R, Schulin R (2013). Zinc and its importance for human health: An integrative review. J Res Med Sci, 18, 144-57.

Rosenberg DW, Giardina C, Tanaka T (2009). Mouse models for the study of colon carcinogenesis. Carcinogenesis, $\mathbf{3 0}$, 183-96.

Rothwell PM, Wilson M, Price JF, et al (2012). Effect of daily aspirin on risk of cancer metastasis: a study of incident cancers during randomised controlled trials. Lancet, 379, 1591-1601.

Rothwell PM, Price JF, Fowkes FG, et al (2012). Short-term effects of daily aspirin on cancer incidence, mortality, and non-vascular death: analysis of the time course of risks and benefits in 51 randomised controlled trials. Lancet, 379, $1602-12$.

Rutkay-Nedecky B, Nejdl L, Gumulec J, et al (2013). The Role of Metallothionein in Oxidative Stress. Int $J \mathrm{Mol} \mathrm{Sci,14}$, 6044-66.

Schmitz KJ, Müller CI, Reis H, et al (2009). Combined analysis of hypoxia-inducible factor 1 alpha and metallothionein indicates an aggressive subtype of colorectal carcinoma. Int J Colorectal Dis, 24, 1287-96.

Sharif R, Thomas P, Zalewski P, Fenech M (2015). Zinc supplementation influences genomic stability biomarkers, antioxidant activity, and zinc transporter genes in an elderly Australian population with low zinc status. Mol Nutr Food Res, 59, 1200-12.

Sozmen M, Erginsoy SD, Cenesiz S, Devrim AK (2005) The protective effect of kefir and vitamin $\mathrm{C}$ on azoxymethane induced toxicity and induction of metallothionein in mice. Scand J Lab Anim Sci, 32, 211-20.

Stephenson CM, Levin RD, Spector T, Lis CG (2013). Phase I clinical trial to evaluate the safety, tolerability, and pharmacokinetics of high-dose intravenous ascorbic acid in patients with advanced cancer. Cancer Chemother
Pharmacol, 72, 139-46.

Sram RJ, Binkova B, RossnerP (2012).Vitamin C for DNA damage prevention. Mutat Res, 733, 39-49.

Szczurek EI, Bjornsson CS, Taylor CG (2001). Dietary zinc deficiency and repletion Modulate metallothionein immunolocalization and concentration in small intestine and liver of rats. $J$ Nutr, 131, 2132-8.

Taketo MM, Edelman W (2009). Mouse models of colon cancer. Gastroenterology, 136, 780- 98.

Thirumoorthy N, Sundar AS, Manisenthil KK, et al (2011). Review of metallothionein isoforms and their role in pathophysiology. World J Surg Oncol, 9, 54.

Williams CD (2013). Antioxidants and prevention of gastrointestinal cancers. Curr Opin Gastroenterol, 29, 195-200.

Zhang X, Giovannucci EL, Smith-Warner SA, et al (2011). A prospective study of intakes of zinc and heme iron and colorectal cancer risk in men and women. Causes Control Cancer, 22, 1627-37.

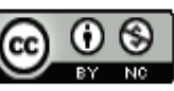

This work is licensed under a Creative Commons AttributionNon Commercial 4.0 International License. 